\title{
The circadian clock goes genomic
}

\author{
Dorothee Staiger, ${ }^{1,2, *}$, Jieun Shin ${ }^{3}$, Mikael Johansson' and Seth J Davis, $3,4, *$
}

\section{Abstract \\ Large-scale biology among plant species, as well as comparative genomics of circadian clock architecture and clock-regulated output processes, have greatly advanced our understanding of the endogenous timing system in plants.}

\section{Introduction}

Plants rely on an endogenous timekeeper to optimally prepare for the recurrent cycles of day and night, light and darkness, energy production and energy consumption, activity of pollinators, as well as seasonal changes that tell them when to flower or shed their leaves [1,2]. The 'circadian' clockwork (from Latin circa diem, about one day) is entrained to the periodic light regime of the environment: plants use this information to control internal processes so that they take place at the most appropriate time of day for maximal output and performance. This global system works at various genomic levels.

The core clockwork consists of negative feedback loops through which clock proteins sustain their own 24-h rhythm [3-6]. In the model plant Arabidopsis thaliana, the Myb-type transcription factors LATE ELONGATED HYPOCOTYL (LHY) and CIRCADIAN CLOCK ASSOCIATED 1 (CCA1) oscillate with a peak around dawn (Figure 1a). LHY and CCA1 activate the expression of four PSEUDO-RESPONSE REGULATORs $(P R R \mathrm{~s})$ that are sequentially expressed, starting with $P R R 9$ in the morning, followed by PRR7, PRR5 and TOC1/PRR1. This activation occurs indirectly via inhibition of the evening complex (EC), which is a repressor of the PRRs (Figure $1 \mathrm{~b}$ ); three proteins, LUX ARRHYTHMO (LUX)/PHYTOCLOCK1 (PCL1) and the plant-specific proteins EARLY FLOWERING 3 (ELF3)

*Correspondence: dorothee.staiger@uni-bielefeld.de; davis@mpipz.mpg.de 'Molecular Cell Physiology, Bielefeld University, Universitaetsstr. 25, 33615 Bielefeld, Germany

${ }^{3}$ Max Planck Institute for Plant Breeding Research, 50829 Cologne, Germany Full list of author information is available at the end of the article and ELF4, interact to form the EC. The PRRs induce the $\mathrm{EC}$ in the late evening, whereas CCA1 and LHY repress EC expression. The EC, in turn, indirectly activates $C C A 1$ and $L H Y$ by directly inhibiting the repressive PRRs. These and other clock proteins regulate rhythmic molecular and biochemical processes in the cell (Figure 1c) (see section 'From a single oscillating mRNA to the rhythmic transcriptome'). These molecular-genetic events have been integrated into quite sophisticated systems models (reviewed at a systems level in Bujdoso and Davis [7]).

Overall, the principles of rhythm generation in plants are the same as in mammals or Drosophila, but the components involved are largely different, pointing to independent origins of the timekeeping mechanisms. In mammals, the core loop comprises the transcription factors CLOCK and BMAL1, which activate the expression of Cryptochrome and Period genes. The PERIOD/ CRYPTOCHROME complex, in turn, represses BMAL1/ CLOCK-mediated transcription of their own genes. Additional feedback loops consisting of transcriptional activators and repressors interlock with this central loop to regulate the expression of the core clock genes (for a detailed description, see Zhang and Kay [8], Staiger and Köster [9], and Dibner et al. [10]).

In this review, we summarize recent insights into the blueprint of the circadian clock and the function of clock proteins based on genomic studies in Arabidopsis and other plant species (Figure 2). Furthermore, we describe how large-scale biology has greatly advanced our understanding of how timing information is translated into rhythmic processes in the plant cell.

\section{From a single oscillating mRNA to the rhythmic transcriptome}

Chronobiology, the discipline of endogenous timekeeping, went molecular with the first demonstration of mRNAs in pea plants that appeared at sunrise and disappeared at sunset, and continued to cycle with a 24-h rhythm even in the absence of a light-dark cycle [11]. It was difficult to appreciate these circadian experiments as they were not just a 'minus light' sample compared with a 'plus light' sample, but required processing of many samples harvested around the clock. A major advance in this sort of approach was to move beyond a gene-by-gene examination. The first circadian microarray study was 


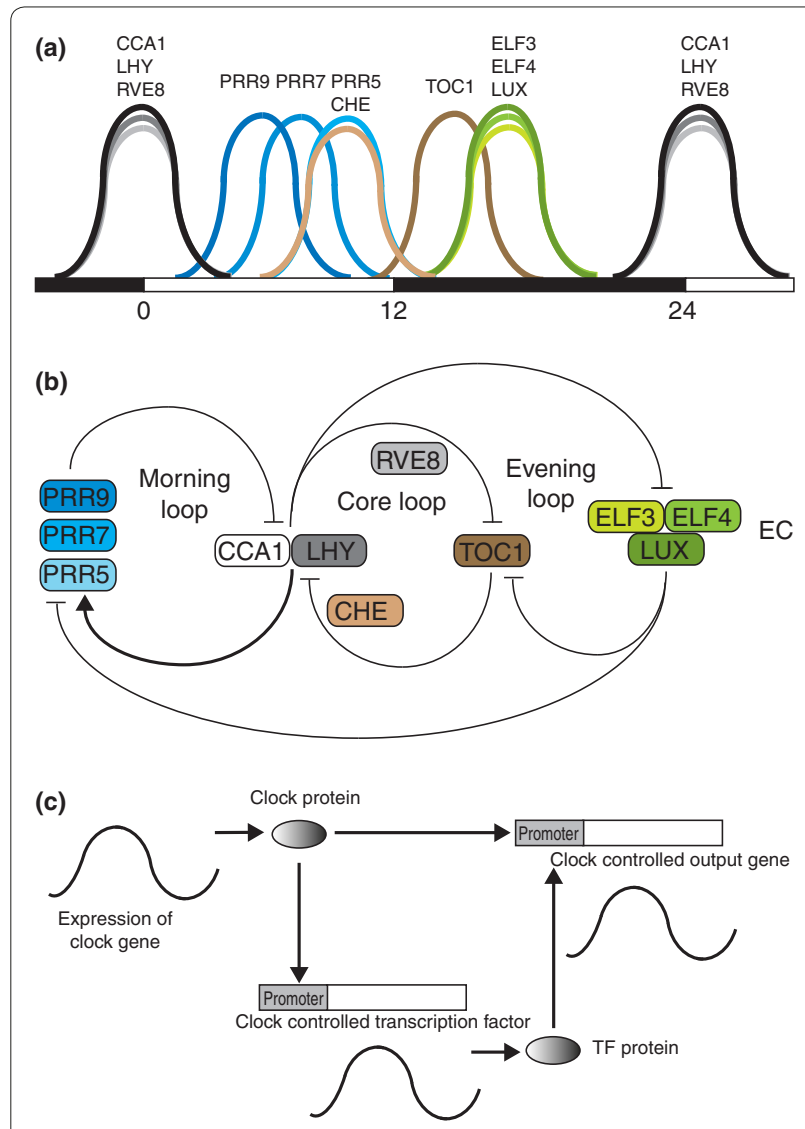

Figure 1. Circadian oscillations in clock gene expression lead to a global rhythm of large parts of the transcriptome. (a) Oscillations of the Arabidopsis thaliana clock genes across the day. The open bar refers to day, the dark bar refers to night. The numbers indicate hours after lights on. Please note that the amplitude of the oscillations is arbitrarily chosen to be equal for all transcripts. (b) Blueprint of the circadian oscillator in Arabidopsis thaliana. The core loop consists of the Myb-type transcription factors CCA1 and LHY, and the Pseudo response regulator TOC1, which reciprocally regulate each others' oscillations. Interconnected with the core loop are the morning and the evening loops. In the morning loop, CCA1 and LHY activate PRR5, PRR7 and PRR9, which in turn leads to inhibition of CCA1 and LHY. In the evening loop, the evening complex (EC), a protein complex consisting of ELF3, ELF4 and LUX, inhibits expression of PRR9 and perhaps other PRRs. EC components are themselves rhythmic through repression by CCA1 and LHY. Additional transcription factors, such as RVE8 and CHE, modulate these interconnected loops. (c) Oscillations in the output genes can be accomplished through direct binding of rhythmically expressed clock proteins to phase modules in their promoters or via intermediate transcription factors (TF). In this way, transcripts are directed to different times of the day. As one example, components involved in metabolizing sugars produced through photosynthesis peak early in the day, and components involved in starch degradation, in turn, peak in the middle of the night [12].

opportunely performed just after the compilation of the Arabidopsis genome [12,13]. Cycling gene clusters could thus be linked to nearby non-coding DNA, and conserved elements in the upstream regions revealed phase-specific promoter elements [12,14-16]. These studies provided valuable insights into the genome-wide mechanism of clock outputs for the first time. Groups of genes that are co-ordinately directed to certain times of the day pointed to entire pathways that were not previously known to be clock-regulated, such as the phenylpropanoid pathway [12].

Subsequently, many homologous genes were found to be clock-regulated and phased to similar times of day in poplar and rice, as they are in Arabidopsis [17]. Furthermore, the same three major classes of cis-regulatory modules of Arabidopsis were found in poplar and rice. The morning module consists of the morning element (CCACAC), which confers expression at the beginning of the day, and a ubiquitous G-box (CACGTG) regulatory element associated with regulation by light and by the phytohormone abscisic acid. The evening module consists of the evening element (AAAATATCT), which confers expression at the end of the day, and the GATA motif, which is associated with light-regulated genes. The midnight modules come in three variants, ATGGCC (PBX), AAACCCT (TBX) and AAGCC (SBX). This points to a strong conservation of clock-regulated transcriptional networks between mono- and dicotyledonous species [17]. As shown in Figure 1c, oscillations of the output genes can be accomplished through direct binding of rhythmically expressed clock proteins to phase modules in the promoters of output genes, or via intermediate transcription factors.

The information from numerous microarray experiments conducted under different light and temperature regimes by the community were assembled into the easyto-use DIURNAL database [18]. This site is widely consulted to check for rhythmic transcript patterns, reflecting the growing awareness of the importance of temporal programs in gene expression [18].

Rhythmically expressed genes in Arabidopsis were found to be over-represented among phytohormone- and stress-responsive pathways. This revealed that endogenous or environmental cues elicit reactions of different intensities depending on the time-of-day $[15,19]$. This socalled 'gating' is thought to optimize the response to a plethora of stimuli impinging on the plant, and may be of particular relevance for sessile organisms [2]. An example of this is how the PRR5, PRR7 and PRR9 proteins contribute to the cold stress response [20]. These PRRs also contribute to coordinating the timing of the tricarboxylic acid cycle [21]. In this way, one set of regulators directly link global gene expression patterns to rhythmic primary metabolism and stress signaling.

A similar systems-based approach identified the circadian clock as a key player in other facets of metabolism, since CCA1 regulates a network of nitrogenresponsive genes throughout the plant [22]. CCA1 also 


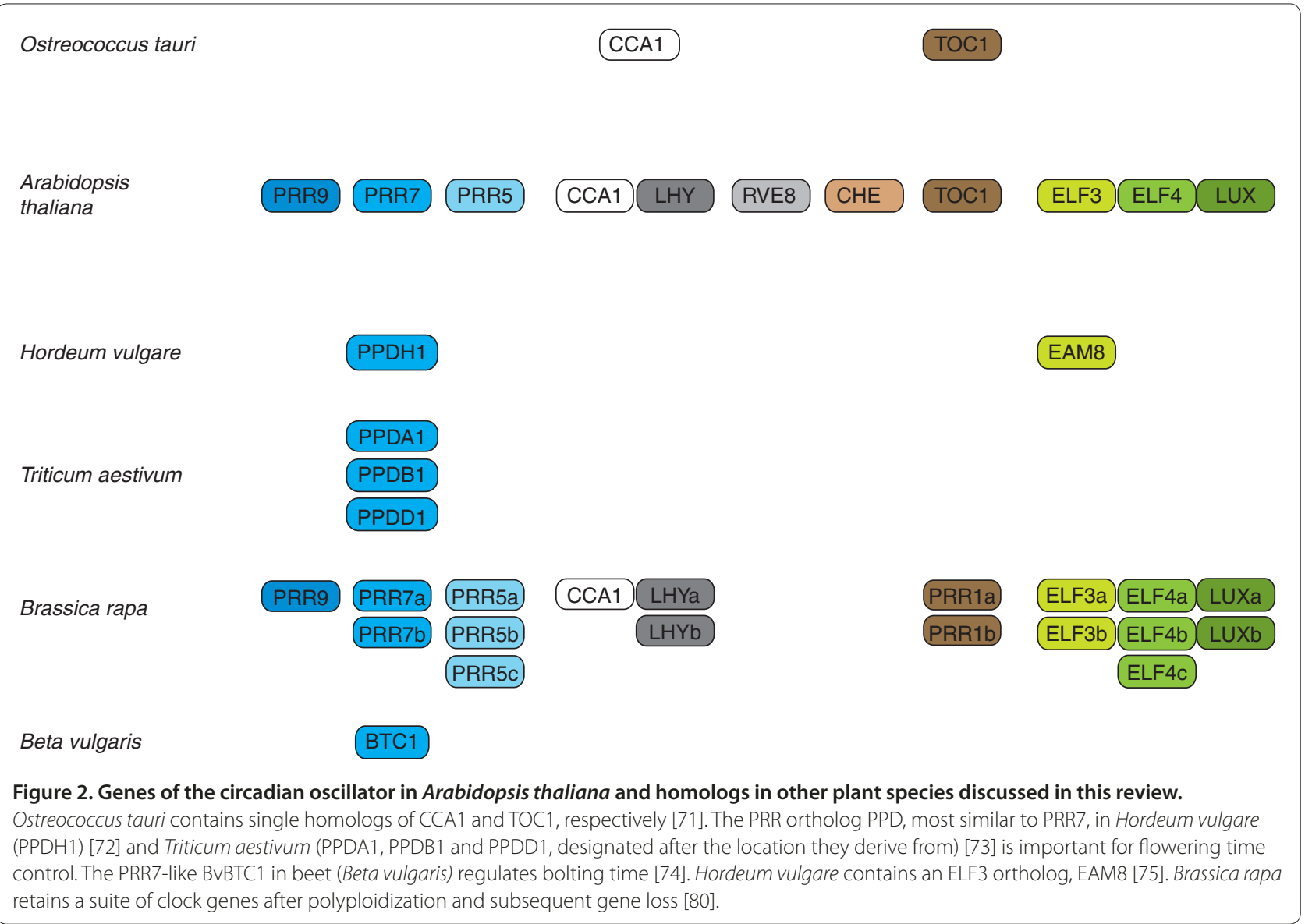

has a role in coordination of the reactive oxygen species response that occurs each day as part of light harvesting for photosynthesis and the reaction to abiotic stress, such as the response to high salt [23]. Another clock-optimized process is the regulation of plant immunity. The defense of Arabidopsis against Pseudomonas syringae or insects depends on the time-of-day of pathogen attack [24-26]. Furthermore, genes that are induced upon infection with the oomycete Hyaloperonospora arabidopsidis, which causes downy mildew disease, have more CCA1 binding sites in their promoters than expected [27]. cca1 mutants show reduced resistance when infected at dawn. Since lhy mutants are not impaired in disease resistance, this points to a specific effect of the CCA1 clock protein rather than a general effect of the clock [27]. Similarly, the RNA-binding protein AtGRP7 (Arabidopsis thaliana glycine-rich RNA binding protein 7 ), which is part of a negative feedback loop downstream of the core oscillator, plays a role in immunity [28-30].

Microarray analysis has also contributed to the question of whether there is one clock for all parts of the plant. Plants, unlike animals, do not have their circadian system organized into a master clock situated in the brain and 'slave' clocks in peripheral organs [31]. However, the differential oscillatory patterns of core clock genes in Arabidopsis shoots and roots point to a distinct clock in roots that runs only on the morning loop [32].

\section{Post-transcriptional control contributes to rhythms of the transcriptome}

Soon after discovering the effect of the clock on transcription, it became apparent that clock-controlled promoter activity does not always lead to detectable oscillations in mRNA steady-state abundance. This was attributable to a long half-life of the transcripts [33]. In Arabidopsis, a global search for short-lived transcripts identified a suite of clock-controlled transcripts. For some of these, the mRNA stability changes over the circadian cycle [34]. Corresponding factors that may coordinately regulate the half-life of sets of transcripts are yet to be identified, although candidates include RNAbinding proteins that themselves undergo circadian oscillations [35].

A prominent role for post-transcriptional control in circadian timekeeping was suggested by the long period phenotype of the prmt5 mutant defective in PROTEIN ARGININE METHYLTRANSFERASE 5 [36-38]. Among the protein substrates of PRMT5 are splicing factors, and 
thus PRMT5 has a global impact on splicing. Alternative splicing of the clock gene PRR9 is affected by loss of PRMT5 and the transcript isoform encoding functional PRR9 is barely detectable in prmt 5 mutants, suggesting that the circadian defect may partly be caused by changes in $P R R 9$ splicing [36]. Additional splicing factors that affect circadian rhythms are SPLICEOSOMAL TIMEKEEPER LOCUS1, the SNW/Ski-interacting protein (SKIP) domain protein SKIP, and the paralogous RNA-binding proteins AtGRP7 and AtGRP8 [39-41]. Notably, AtGRP7 and $A t$ GRP8 form a feedback loop through unproductive alternative splicing and decay of transcript isoforms with a premature termination codon, associating for the first time nonsense-mediated decay with the circadian system [42,43].

In another approach, a high-resolution RT-PCR panel based on fluorescently labeled amplicons was used to systematically monitor alternative splicing of the core oscillator genes [44]. Alternative splicing events were observed 63 times, and of these, at least 13 were affected by low temperature. This suggested that alternative splicing might serve to adjust clock function to temperature changes. More recently, RNA-Seq analyses identified alternative splicing of many clock genes, and an event leading to the retention of an intron in CCA1 was conserved across different plant species [45]. In the future, a systematic comparison of alternative splicing networks (both for core clock genes and clock output genes) to the corresponding transcriptional programs will unravel the contribution of alternative splicing to the rhythms in transcript and protein abundance.

To date, the extent to which proteins undergo circadian oscillations in the plant cell has not been systematically studied. An initial proteomic study in rice revealed a difference in expression phases between mRNAs and proteins, suggesting regulation at the post-transcriptional, translational and post-translational levels [46]. Uncoupling of protein rhythms from mRNA rhythms has also been observed in mouse liver, where $20 \%$ of soluble proteins show a rhythm in protein abundance but only half of them originate from rhythmic transcripts [47].

\section{Noncoding RNAs and the plant clock - a not-so-well defined connection}

A prominent class of small noncoding RNAs are microRNAs (miRNAs), which are 19 to 22 nucleotide long single-stranded RNAs that base-pair with mRNA targets and thereby control the level of target transcripts or the level of translation of these mRNAs [48]. miRNAs that oscillate across the circadian cycle have been widely described in mammals and Drosophila. In these organisms, miRNAs target clock components and play a role in entrainment or regulation of clock output $[49,50]$.

In Arabidopsis, a suite of miRNAs was interrogated for rhythmic expression. Using tiling arrays, miR157A,
miR158A, miR160B and miR167D were found to be clock-controlled [51]. On the other hand, miR171, miR398, miR168 and miR167 oscillate diurnally but are not controlled by the clock [52]. The functional implications of these mRNA oscillations are not yet clear. Based on the prominent role miRNAs play in modulating the circadian clock in Drosophila or mammals, such a function is to be expected in plants, where miRNAs so far have a demonstrated role only in clock output, such as seasonal timing of flowering [53].

Another class of noncoding RNAs is naturally occurring antisense transcripts (NATs). In Arabidopsis, rhythmic NATs were detected for $7 \%$ of the protein coding genes using tiling arrays [51]. Among these were the clock proteins LHY and CCA1, TOC1, PRR3, PRR5, PRR7 and PRR9. In the bread mold Neurospora crassa, NATs have been implicated in clock regulation. Suites of large antisense transcripts overlap the clock gene frequency in opposite phase to sense frq. These NATs are also induced by light and thus appear to play a role in entrainment by light signals [54]. A causal role for noncoding RNAs in the plant circadian system has yet to be established.

\section{Forward and reverse genetics to define the core oscillator mechanism}

Forward genetic screens of mutagenized plants carrying clock-controlled promoters fused to the LUCIFERASE reporter for aberrant timing of bioluminescence were instrumental to uncover the first clock genes, TOC1, ZEITLUPE and LUX/PCL1 [55-58]. Likely because of extensive redundancy in plant genomes, most other clock genes were identified by reverse genetic approaches and genome-wide studies. In fact, up to $5 \%$ of transcription factors have the capacity to contribute to proper rhythm generation [59]. A yeast one hybrid screen of a collection of transcription factors for their binding to the CCA1/ LHY regulatory regions revealed CIRCADIAN HIKING EXPEDITION (CHE) as a modulator of the clock [60].

These CHE studies attempted to bridge TOC1 with the regulation of CCA1/LHY, but failed to fully explain the effect of TOC1 on CCA1/LHY expression. Subsequently, chromatin immunoprecipitation (ChIP)-Seq showed that TOC1 directly associates with the CCA1 promoter, and this interaction is not dependent on CHE $[61,62]$. Thus, while CHE is not generally seen as a core clock component, its analysis revealed that genomic approaches can feasibly interrogate the capacity of a given transcription factor to modulate clock performance. Genome-wide analysis of cis-elements in clock-controlled promoters should identify the motifs that control rhythmic RNA expression of a clock-controlled gene, and this facilitates the identification of the trans factors that create such rhythms (Figure 1c). 


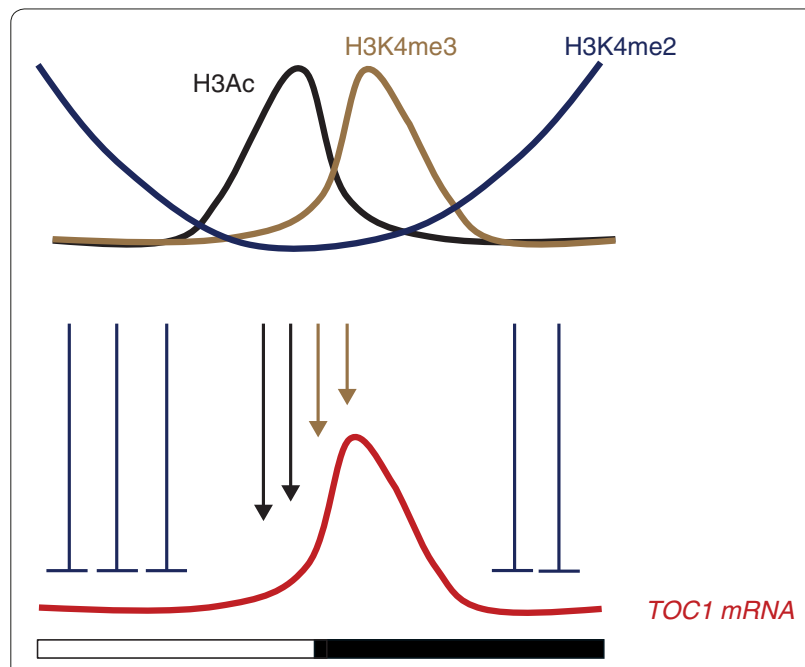

Figure 3. Scheme of the dynamics of chromatin marks and TOC1 gene expression across the day. The marks for active chromatin, $\mathrm{H} 3 \mathrm{Ac}$ and $\mathrm{H} 3 \mathrm{~K} 4 \mathrm{me} 3$ (top), sequentially correlate with peaks in clock gene mRNA accumulation (bottom), whereas the mark for repressive chromatin, H3K4me2 (top), inversely correlates with TOC1 mRNA accumulation (bottom). The open bar refers to day, the dark bar refers to night.

ChIP-Seq revealed that PRR5 functions as a transcriptional repressor to control the timing of target genes [63]. It can be expected that the global DNA-binding activity of all core-clock components will be rapidly assembled and this will be associated with the roles of each factor in regulating global transcription, accounting for up to $30 \%$ of all transcripts [64].

\section{Epigenetic regulation - a facilitator to rhythmic gene expression?}

Rhythmic clock gene transcription is accompanied by histone modification at the 5' ends. For example, in mammals transcriptional activity of the promoters of the Period clock genes coincides with rhythmic acetylation of histone H3 lysine 9 that is dependent on the histone acetyltransferase activity of CLOCK [65]. In Arabidopsis, it was shown that acetylation of $\mathrm{H} 3$ at the TOC1 promoter is rhythmically regulated, and this positively correlates with TOC1 transcription [66]. Later, the chromatin of other clock genes, including CCA1, LHY, PRR9, $P R R 7$ and $L U X$, was additionally found to be rhythmically modulated by multiple types of histone modification $[67,68]$ (Figure 3). The level of the transcription activating marks, acetylation on $\mathrm{H} 3(\mathrm{H} 3 \mathrm{ac})$ and tri-methylation on $\mathrm{H} 3$ lysine 4 (H3K4me3), increases when these clock genes are actively transcribed, whereas the level of the transcription repressing marks H3K36me2 and H3K4me2 reach their peak when the genes are at their trough $[67,68]$. These histone modifications are found to be dynamically controlled such that $\mathrm{H} 3$ is sequentially changed as $\mathrm{H} 3 \mathrm{ac} \rightarrow \mathrm{H} 3 \mathrm{~K} 4 \mathrm{me} 3 \rightarrow \mathrm{H} 3 \mathrm{~K} 4 \mathrm{me} 2$ within a rhythmic period [68]. The level of other chromatin marks such as H4Ac, H3K27me3, H3K27me2 and H3K9me3 at the clock gene promoter region does not change rhythmically $[67,68]$.

So far, a number of clock components have been shown to be required to modify histones at the appropriate time. For example, CCA1 antagonizes H3Ac at the TOC1 promoter [66]. In contrast, REVEILLE8 (RVE8), a MYB-like transcription factor similar to CCA1 and LHY, promotes H3Ac at the TOC1 promoter, predominantly during the day [69]. However, it is unclear if CCA1 and RVE8 cause the histone modification at the TOC1 promoter, or if histone modification allows CCA1 or RVE8 to actively participate in regulation of TOC1 transcription, respectively. The underlying molecular mechanism of the temporal histone modification and components involved are currently elusive. Furthermore, it remains to be shown whether other histone modifications, such as phosphorylation, ubiquitination or sumoylation [70], also contribute to the clock gene expression and change across the day.

\section{Comparative genomics}

The availability of an ever-increasing number of sequenced plant genomes has made it possible to track down the evolution of core clock genes. The Arabidopsis core oscillator comprises families of proteins that are assumed to have partially redundant functions $[1,3]$. The founding hypothesis was that the higher-land-plant clock derived from algae. The green alga Ostreococcus tauri, the smallest living eukaryote with its $12.5 \mathrm{Mb}$ genome $(10 \%$ of Arabidopsis) has only a CCA1 homolog, forming a simple two-component feedback-loop with a TOC1 homolog, the only PRR-like gene found in Ostreococcus [71]. This supported that the hypothesis that the CCA1TOC1 cycle is the ancestral oscillator (Figure 2).

Recent efforts to clone crop-domestication genes have revealed that ancient and modern breeding has selected variants in clock components. The most notable examples include the transitions of barley and wheat as cereals and alfalfa and pea as legumes from the Fertile Crescent to temperate Europe. This breeding and seed trafficking was arguably the greatest force in Europe leading the transition from nomadic to civilized lifestyles. It is known that ancestral barley and wheat are what are now called the winter varieties. The common spring varieties arose as late flowering cultivars, which profit from the extended light and warmth of European summers over that of the Middle East. That occurred from a single mutation in barley (Hordeum vulgare) in a PRR ortholog most similar to PRR7 termed Ppd-1 (Photoperiod-1) (Figure 2) [72]. In wheat (Triticum aestivum), since it is polyploid and recessive mutations rarely have any phenotypic impact, breeders selected promoter mutations at PPD that led to 
dominant late-flowering [73]. Interestingly, in the beet Beta vulgaris, a PRR7-like gene named BOLTING TIME CONTROL1 $(B v B T C 1)$ is involved in the regulation of bolting time, mediating responses to both long days and vernalization [74]. Evolution at PRR7 is thus a recurrent event in plant domestication.

As barley (Hordeum vulgare) moved north, early flowering was selected in a late-flowering context due to the presence of the spring allele at ppdh1. Mutations in the barley ELF3 ortholog, termed EAM8 (Figure 2), were selected [75]. Interestingly, the migration of bean and alfalfa to temperate Europe also coincided with ELF3 mutations [76]. In Asia, rice varieties in domestication have also mapped to the ELF3 locus [77]. It will be intriguing to assess the genome-wide population structure of clock gene variation as a possible driving force in species migration over latitude and altitude. Genomewide efforts to explore this show that such studies have merit [78].

One identifying feature of plants within clades of multicellular organisms is the possibility of fertile polyploids. It is speculated that, over evolutionary time, all higher-land plants were at one time polyploid, and indeed, it has been estimated that up to $80 \%$ of extant plant species are in a non-diploid state [79]. This raises several confounding features on the genome. For one, in autopolyploids, derived from an expansion of genomes derived from one species, the process of going from $2 \times$ to $4 \times$ obviously increases the copy number of all genes by twofold. One report to examine this comes from the comparison of the Brassica rapa oscillator repertory [80]. On average, it is possible for this species to have threefold more of an individual gene over Arabidopsis. However, this is not always the case, as gene loss of these redundant copies has occurred at numerous loci [81]. By examining the probability of gene presence, it has been shown that the retention of clock genes has been more highly favored than the retention of genes randomly sampled from the genome [81]; this was not a linkage disequilibrium effect, as even the neighboring genes, as known by synteny, were retained at a lower rate. Thus, Brassica rapa has gained fitness by keeping additional copies of clock genes (Figure 2). Why that is awaits testing.

In allopolyploids that arise from the intercrossing of species, the clock confronts allele choice issues between the potentially conflicting parental genomes. Allopolyploids are common in nature, are often easy to recreate in the lab, and are often more vigorous than the parents. Using a newly generated allopolyploid, the role of the clock in providing a genome-wide fitness was assessed $[75,76]$. Epigenetic modification at two morning clock genes was found to associate with vigor through regulation of metabolic processes [82]. In subsequent studies, this was further related to stress response pathways in a genome-wide analysis of mRNA decay [83]. Thus, genome-wide polyploidy acts early on clock genes to partition metabolism and stress signaling.

\section{Outlook}

High-throughput approaches have greatly advanced our understanding of the pervasive effect of the clock on the transcriptome and molecular underpinnings of rhythms in promoter activity. However, our knowledge of rhythms in protein abundance conferred by subsequent layers of regulation and of small RNA regulation in the plant circadian system is underdeveloped. Comparative genomics among different plant species have pointed to divergences in clock-output processes, and perhaps in the clock mechanism itself. Relating the orthologous function of a given clock protein across the function of the plant genomes will undoubtedly continue to require large-scale genomics.

\section{Abbreviations}

AtGRP, Arabidopsis thaliana glycine-rich RNA binding protein; CCA1, circadian clock associated 1; CHE, circadian hiking expedition; EC, evening complex; ELF, early flowering; LHY, late elongated hypocotyl; LUX, lux arrhythmo; NAT, naturally occurring antisense transcript; PRMT5, protein arginine methyltransferase 5; PRR, pseudo-response regulator; RVE8, reveille 8; TOC1, timing of $C A B$ expression 1 .

\section{Competing interests}

The authors declare that they have no competing interests.

\section{Acknowledgements}

Research in our laboratories is supported by the DFG (STA653 and SPP1530) to DS and (DA1041/4, SFB635, and SPP1530) to SJD. JS and MJ both recognize Alexander von Humboldt support.

\section{Author details}

'Molecular Cell Physiology, Bielefeld University, Universitaetsstr. 25, 33615 Bielefeld, Germany. ${ }^{2}$ Institute for Genome Research and Systems Biology, CeBiTec, 33615 Bielefeld, Germany. ${ }^{3}$ Max Planck Institute for Plant Breeding Research, 50829 Cologne, Germany. ${ }^{4}$ Department of Biology, University of York, Wentworth Way, York YO10 5DD, UK.

Published: 24 June 2013

\section{References}

1. McClung CR: The genetics of plant clocks. Adv Genet 2011, 74:105-139.

2. Gardner MJ, Hubbard KE, Hotta CT, Dodd AN, Webb AA: How plants tell the time. Biochem J 2006, 397:15-24.

3. Nagel DH, Kay SA: Complexity in the wiring and regulation of plant circadian networks. Curr Biol 2012, 22:R648-R657.

4. Troncoso-Ponce MA, Mas P: Newly described components and regulatory mechanisms of circadian clock function in Arabidopsis thaliana. Mol Plant 2012, 5:545-553

5. Pokhilko A, Fernandez AP, Edwards KD, Southern MM, Halliday KJ, Millar AJ: The clock gene circuit in Arabidopsis includes a repressilator with additional feedback loops. Mol Syst Bio/ 2012, 8:574.

6. Herrero E, Davis SJ: Time for a nuclear meeting: protein trafficking and chromatin dynamics intersect in the plant circadian system. Mol Plant 2012, 5:554-565.

7. Bujdoso N, Davis SJ: Mathematical modeling of an oscillating gene circuit to unravel the circadian-clock network of Arabidopsis thaliana. Front Plant Sci2013, 4:3

8. Zhang EE, Kay SA: Clocks not winding down: unravelling circadian networks. Nat Rev Mol Cell Biol 2010, 11:764-776.

9. Staiger D, Köster T: Spotlight on post-transcriptional control in the circadian system. Cell Mol Life Sci 2011, 68:71-83. 
10. Dibner C, Schibler U, Albrecht U: The mammalian circadian timing system: organization and coordination of central and peripheral clocks. Annu Rev Physiol 2010, 72:517-549.

11. Kloppstech K: Diurnal and circadian rhythmicity in the expression of lightinduced plant nuclear messenger RNAs. Planta 1985, 165:502-506.

12. Harmer SL, Hogenesch JB, Straume M, Chang HS, Han B, Zhu T, Wang X, Kreps JA, Kay SA: Orchestrated transcription of key pathways in Arabidopsis by the circadian clock. Science 2000, 290:2110-2113

13. Arabidopsis Genome Initiative: Analysis of the genome sequence of the flowering plant Arabidopsis thaliana. Nature 2000, 408:796-815.

14. Michael TP, McClung CR: Phase-specific circadian clock regulatory elements in Arabidopsis. Plant Physiol 2002, 130:627-638.

15. Covington MF, Maloof JN, Straume M, Kay SA, Harmer SL: Global transcriptome analysis reveals circadian regulation of key pathways in plant growth and development. Genome Bio/ 2008, 9:R130.

16. Michael TP, Mockler TC, Breton G, McEntee C, Byer A, Trout JD, Hazen SP, Shen R, Priest HD, Sullivan CM, Givan SA, Yanovsky M, Hong F, Kay SA, Chory J: Network discovery pipeline elucidates conserved time-of-day-specific cis-regulatory modules. PLOS Genet 2008, 4:e14.

17. Filichkin SA, Breton G, Priest HD, Dharmawardhana P, Jaiswal P, Fox SE, Michael TP, Chory J, Kay SA, Mockler TC: Global profiling of rice and poplar transcriptomes highlights key conserved circadian-controlled pathways and cis-regulatory modules. PLoS One 2011, 6:e16907.

18. Mockler TC, Michael TP, Priest HD, Shen R, Sullivan CM, Givan SA, McEntee C, Kay SA, Chory J: The diurnal project: diurnal and circadian expression profiling, model-based pattern matching, and promoter analysis. Cold Spring Harbor Symp Quant Biol 2007, 72:353-363.

19. Covington MF, Harmer SL: The circadian clock regulates auxin signaling and responses in Arabidopsis. PLOS Bio/ 2007, 5:e222.

20. Nakamichi N, Kiba T, Henriques R, Mizuno T, Chua NH, Sakakibara H: PSEUDO-RESPONSE REGULATORS 9, 7, and 5 are transcriptional repressors in the arabidopsis circadian clock. Plant Cell 2010, 22:594-605.

21. Fukushima A, Kusano M, Nakamichi N, Kobayashi M, Hayashi N, Sakakibara H, Mizuno T, Saito K: Impact of clock-associated Arabidopsis pseudo-response regulators in metabolic coordination. Proc Natl Acad Sci U S A 2009, 106:8791.

22. Gutierrez RA, Stokes TL, Thum K, Xu X, Obertello M, Katari MS, Tanurdzic M, Dean A, Nero DC, McClung CR, Conuzzi GM: Systems approach identifies an organic nitrogen-responsive gene network that is regulated by the master clock control gene CCA1. Proc Natl Acad Sci U S A 2008, 105:4939-4944.

23. Lai AG, Doherty CJ, Mueller-Roeber B, Kay SA, Schippers JHM, Dijkwel PP: CIRCADIAN CLOCK-ASSOCIATED 1 regulates ROS homeostasis and oxidative stress responses. Proc Natl Acad Sci U S A 2012, 109:17129-17134.

24. Bhardwaj V, Meier S, Petersen LN, Ingle RA, Roden LC: Defence responses of Arabidopsis thaliana to infection by Pseudomonas syringae are regulated by the circadian clock. PLoS One 2011, 6:e26968.

25. Goodspeed D, Chehab EW, Min-Venditti A, Braam J, Covington MF: Arabidopsis synchronizes jasmonate-mediated defense with insect circadian behavior. Proc Natl Acad Sci U S A 2012, 109:4674-4677.

26. Shin J, Heidrich K, Sanchez-Villarreal A, Parker JE, Davis SJ: TIME FOR COFFEE represses accumulation of the MYC2 transcription factor to provide timeof-day regulation of jasmonate signaling in arabidopsis. Plant Cell 2012, 24:2470-2482

27. Wang W, Barnaby JY, Tada Y, Li H, Tor M, Caldelari D, Lee D-u, Fu X-D, Dong X: Timing of plant immune responses by a central circadian regulator. Nature 2011, 470:110-114

28. Fu ZQ, Guo M, Jeong BR, Tian F, Elthon TE, Cerny RL, Staiger D, Alfano JR: A type III effector ADP-ribosylates RNA-binding proteins and quells plant immunity. Nature 2007, 447:284-288.

29. Streitner C, Hennig L, Korneli C, Staiger D: Global transcript profiling of transgenic plants constitutively overexpressing the RNA-binding protein AtGRP7. BMC Plant Biol 2010, 10:221

30. Nicaise V, Joe A, Jeong B, Korneli C, Boutrot F, Wested I, Staiger D, Alfano JR, Zipfel C: Pseudomonas HopU1 affects interaction of plant immune receptor mRNAs to the RNA-binding protein GRP7. EMBO J 2013, 32:701-712.

31. McWatters HG, Roden LC, Staiger D: Picking out parallels: plant circadian clocks in context. Philos Trans R Soc Lond B Bio/ Sci 2001, 356:1735-1743.

32. James AB, Monreal JA, Nimmo GA, Kelly CL, Herzyk P, Jenkins Gl, Nimmo HG: The circadian clock in Arabidopsis roots is a simplified slave version of the clock in shoots. Science 2008, 322:1832-1835.
33. Wuarin J, Falvey E, Lavery D, Talbot D, Schmidt E, Ossipow V, Fonjallaz P Schibler $\mathrm{U}$ : The role of the transcriptional activator protein DBP in circadian liver gene expression. J Cell Sci 1992, 16:123-127.

34. Lidder P, Gutierrez RA, Salome PA, McClung CR, Green PJ: Circadian control of messenger RNA stability. Association with a sequence-specific messenger RNA decay pathway. Plant Physio/ 2005, 138:2374-2385.

35. Staiger D: RNA-binding proteins and circadian rhythms in Arabidopsis thaliana. Philos Trans R Soc Lond B Biol Sci 2001, 356:1755-1759.

36. Sanchez SE, Petrillo E, Beckwith EJ, Zhang X, Rugnone ML, Hernando CE, Cuevas JC, Godoy Herz MA, Depetris-Chauvin A, Simpson CG, Brown JW, Cerdán PD, Borevitz JO, Mas P, Ceriani MF, Kornblihtt AR, Yanovsky MJ: A methyl transferase links the circadian clock to the regulation of alternative splicing. Nature 2010, 468:112-116.

37. Hong S, Song HR, Lutz K, Kerstetter RA, Michael TP, McClung CR: Type II protein arginine methyltransferase 5 (PRMT5) is required for circadian period determination in Arabidopsis thaliana. Proc Natl Acad Sci U S A 2010 107:21211-21216.

38. Deng X, Gu L, Liu C, Lu T, Lu F, Lu Z, Cui P, Pei Y, Wang B, Hu S, Cao C: Arginine methylation mediated by the Arabidopsis homolog of PRMT5 is essential for proper pre-mRNA splicing. Proc Natl Acad Sci U S A 2010, 107:19114-19119.

39. Jones MA, Williams BA, McNicol J, Simpson CG, Brown JWS, Harmer SL: Mutation of arabidopsis SPLICEOSOMAL TIMEKEEPER LOCUS1 causes circadian clock defects. Plant Cell 2012, 24:4907-4916.

40. Wang X, Wu F, Xie Q, Wang H, Wang Y, Yue Y, Gahura O, Ma S, Liu L, Cao Y, Jiao Y, Puta F, McClung CR, Xu X, Ma L: SKIP is a component of the spliceosome linking alternative splicing and the circadian clock in Arabidopsis. Plant Cell 2012, 24:3278-3295

41. Streitner C, Köster T, Simpson CG, Shaw P, Danisman S, Brown JWS, Staiger D: An hnRNP-like RNA-binding protein affects alternative splicing by in vivo interaction with target transcripts in Arabidopsis thaliana. Nucleic Acids Res 2012, 40:11240-11255

42. Schöning JC, Streitner C, Meyer IM, Gao Y, Staiger D: Reciprocal regulation of glycine-rich RNA-binding proteins via an interlocked feedback loop coupling alternative splicing to nonsense-mediated decay in Arabidopsis. Nucleic Acids Res 2008, 36:6977-6987.

43. Schmal C, Reimann P, Staiger D: A circadian clock-regulated toggle switch explains AtGRP7 and AtGRP8 oscillations in Arabidopsis thaliana. PLoS Comput Bio/ 2013, 9:e1002986

44. James AB, Syed NH, Bordage S, Marshall J, Nimmo GA, Jenkins Gl, Herzyk P, Brown JWS, Nimmo HG: Alternative splicing mediates responses of the Arabidopsis circadian clock to temperature changes. Plant Cell 2012, 24:961-981.

45. Filichkin SA, Priest HD, Givan SA, Shen R, Bryant DW, Fox SE, Wong WK, Mockler TC: Genome-wide mapping of alternative splicing in Arabidopsis thaliana. Genome Res 2010, 20:45-58

46. Hwang HJ, Cho M-H, Hahn B-S, Lim H, Kwon Y-K, Hahn T-R, Bhoo SH: Proteomic identification of rhythmic proteins in rice seedlings. Biochim Biophys Acta 2011, 1840:470-479.

47. Reddy AB, Karp NA, Maywood ES, Sage EA, Deery M, O'Neill JS, Wong GK, Chesham J, Odell M, Lilley KS, Kyriacou CP, Hastings MH: Circadian orchestration of the hepatic proteome. Curr Bio/ 2006, 16:1107-1115

48. Chen X: Small RNAs and their roles in plant development. Annu Rev Cell Dev Biol 2009, 25:21-44

49. Gatfield D, Le Martelot G, Vejnar CE, Gerlach D, Schaad O, Fleury-Olela F, Ruskeepää AL, Oresic M, Esau CC, Zdobnov EM, Schibler U: Integration of microRNA miR-122 in hepatic circadian gene expression. Genes Dev 2009, 23:1313-1326

50. Alvarez-Saavedra M, Antoun G, Yanagiya A, Oliva-Hernandez R, CornejoPalma D, Perez-Iratxeta C, Sonenberg N, Cheng HY: miRNA-132 orchestrates chromatin remodeling and translational control of the circadian clock. Hum Mol Genet 2011, 20:731-751.

51. Hazen SP, Naef F, Quisel T, Gendron JM, Chen H, Ecker JR, Borevitz JO, Kay SA: Exploring the transcriptional landscape of plant circadian rhythms using genome tiling arrays. Genome Bio/ 2009, 10:R17.

52. Sire C, Moreno AB, Garcia-Chapa M, Lopez-Moya JJ, San Segundo B: Diurnal oscillation in the accumulation of Arabidopsis microRNAs, miR167, miR168, miR171 and miR398. FEBS Lett 2009, 583:1039-1044

53. Jung $\mathrm{JH}$, Seo YH, Seo PJ, Reyes JL, Yun J, Chua NH, Park CM: The GIGANTEAregulated MicroRNA172 mediates photoperiodic flowering independent of CONSTANS in Arabidopsis. Plant Cell 2007, 19:2736-2748. 
54. Kramer C, Loros JJ, Dunlap JC, Crosthwaite SK: Role for antisense RNA in regulating circadian clock function in Neurospora crassa. Nature 2003, 421:948-952.

55. Hazen SP, Schultz TF, Pruneda-Paz JL, Borevitz JO, Ecker JR, Kay SA: LUX ARRHYTHMO encodes a Myb domain protein essential for circadian rhythms. Proc Natl Acad Sci U S A 2005, 102:10387-10392.

56. Somers DE, Schultz TF, Milnamow M, Kay SA: ZEITLUPE encodes a novel clock-associated PAS protein from Arabidopsis. Cell 2000, 101:319-329.

57. Onai K, Ishiura M: PHYTOCLOCK 1 encoding a novel GARP protein essential for the Arabidopsis circadian clock. Genes Cells 2005, 10:963-972.

58. Millar AJ, Carre IA, Strayer CA, Chua NH, Kay SA: Circadian clock mutants in Arabidopsis identified by luciferase imaging. Science 1995, 267:1161-1163.

59. Hanano S, Stracke R, Jakoby M, Merkle T, Domagalska MA, Weisshaar B, Davis SJ: A systematic survey in Arabidopsis thaliana of transcription factors that modulate circadian parameters. BMC Genomics 2008, 9:182.

60. Pruneda-Paz JL, Breton G, Para A, Kay SA: A functional genomics approach reveals $\mathrm{CHE}$ as a component of the Arabidopsis circadian clock. Science 2009, 323:1481-1485.

61. Huang W, Perez-Garcia P, Pokhilko A, Millar AJ, Antoshechkin I, Riechmann JL, Mas P: Mapping the core of the Arabidopsis circadian clock defines the network structure of the oscillator. Science 2012, 336:75-79.

62. Gendron JM, Pruneda-Paz JL, Doherty CJ, Gross AM, Kang SE, Kay SA: Arabidopsis circadian clock protein, TOC1, is a DNA-binding transcription factor. Proc Natl Acad Sci U S A 2012, 109:3167-3172.

63. Nakamichi N, Kiba T, Kamioka M, Suzuki T, Yamashino T, Higashiyama T, Sakakibara H, Mizuno T: Transcriptional repressor PRR5 directly regulates clock-output pathways. Proc Natl Acad Sci U S A 2012, 109:17123-17128.

64. Michael TP, McClung CR: Enhancer trapping reveals widespread circadian clock transcriptional control in arabidopsis. Plant Physio/ 2003, 132:629-639.

65. Doi M, Hirayama J, Sassone-Corsi P: Circadian regulator CLOCK is a histone acetyltransferase. Cell 2006, 125:497-508.

66. Perales M, Mas P: A functional link between rhythmic changes in chromatin structure and the Arabidopsis biological clock. Plant Cell 2007, 19:2111-2113

67. Song H-R, Noh Y-S: Rhythmic oscillation of histone acetylation and methylation at the Arabidopsis central clock loci. Mol Cells 2012, 34:279-287.

68. Malapeira J, Khaitova LC, Mas P: Ordered changes in histone modifications at the core of the Arabidopsis circadian clock. Proc Natl Acad Sci U S A 2012 109:21540-21545

69. Farinas B, Mas P: Functional implication of the MYB transcription factor RVE8/LCL5 in the circadian control of histone acetylation. Plant J 2011, 66:318-329.

70. Liu C, Lu F, Cui X, Cao X: Histone methylation in higher plants. Annu Rev Plant Biol 2010, 61:395-420

71. Corellou F, Schwartz C, Motta JP, Djouani-Tahri EB, Sanchez F, Bouget FY: Clocks in the green lineage: comparative functional analysis of the circadian architecture of the picoeukaryote Ostreococcus. Plant Cell 2009, 21:3436-3449.

72. Turner A, Beales J, Faure S, Dunford RP, Laurie DA: The pseudo-response regulator $\mathrm{Ppd}-\mathrm{H} 1$ provides adaptation to photoperiod in barley. Science 2005, 310:1031-1034.

73. Shaw LM, Turner AS, Laurie DA: The impact of photoperiod insensitive Ppd-1a mutations on the photoperiod pathway across the three genomes of hexaploid wheat (Triticum aestivum). Plant J 2012, 71:71-84

74. Pin PA, Zhang W, Vogt SH, Dally N, Büttner B, Schulze-Buxloh G, Jelly NS, Chia TY, Mutasa-Göttgens ES, Dohm JC, Himmelbauer H, Weisshaar B, Kraus J, Gielen JJ, Lommel M, Weyens G, Wahl B, Schechert A, Nilsson O, Jung C, Kraft T, Müller AE: The role of a pseudo-response regulator gene in life cycle adaptation and domestication of beet. Curr Biol 2012, 22:1095-1101.

75. Faure S, Turner AS, Gruszka D, Christodoulou V, Davis SJ, von Korff M, Laurie DA: Mutation at the circadian clock gene EARLY MATURITY 8 adapts domesticated barley (Hordeum vulgare) to short growing seasons. Proc Natl Acad Sci U S A 2012, 109:8328-8333.

76. Weller JL, Liew LC, Hecht VF, Rajandran V, Laurie RE, Ridge S, Wenden B, Vander Schoor JK, Jaminon O, Blassiau C, Dalmais M, Rameau C, Bendahmane A, Macknight RC, Lejeune-Hénaut I: A conserved molecular basis for photoperiod adaptation in two temperate legumes. Proc Natl Acad Sci U S A 2012, 109:21158-21163.

77. Matsubara K, Ogiso-Tanaka E, Hori K, Ebana K, Ando T, Yano M: Natural variation in Hd17, a homolog of Arabidopsis ELF3 that is involved in rice photoperiodic flowering. Plant Cell Physio/ 2012, 53:709-716.

78. Higgins JA, Bailey PC, Laurie DA: Comparative genomics of flowering time pathways using Brachypodium distachyon as a model for the temperate grasses. PLoS One 2010, 5:e10065.

79. Meyers LA, Levin DA: On the abundance of polyploids in flowering plants. Evolution 2006, 60:1198-1206.

80. Lou P, Wu J, Cheng F, Cressman LG, Wang X, McClung CR: Preferential retention of circadian clock genes during diploidization following whole genome triplication in Brassica rapa. Plant Cell 2012, 24:2415-2426.

81. Lou P, Xie Q, Xu X, Edwards CE, Brock MT, Weinig C, McClung CR: Genetic architecture of the circadian clock and flowering time in Brassica rapa. Theor App/ Genet 2011, 123:397-409.

82. Ni Z, Kim ED, Ha M, Lackey E, Liu J, Zhang Y, Sun Q, Chen ZJ: Altered circadian rhythms regulate growth vigour in hybrids and allopolyploids. Nature 2008, 457:327-331.

83. Kim E-D, Chen ZJ: Unstable transcripts in Arabidopsis allotetraploids are associated with nonadditive gene expression in response to abiotic and biotic stresses. PLoS One 2012, 6:e24251.

doi:10.1186/gb-2013-14-6-208

Cite this article as: Staiger D, et al.: The circadian clock goes genomic. Genome Biology 2013, 14:208. 